OPEN ACCESS

Edited by:

Limor Avivi-Arber,

Faculty of Dentistry, University of

Toronto, Canada

Reviewed by:

Antonina Luca,

University of Catania, Italy

Kaija Hiltunen,

University of Helsinki, Finland

Eef Hogervorst,

Loughborough University,

United Kingdom

*Correspondence:

Suzanne Delwel

s.delwel@vu.nl

Received: 02 December 2019

Accepted: 25 June 2020

Published: 09 September 2020

Citation:

Delwel S, Maier AB, Parvaneh D,

Meijers J, Scherder EJA and

Lobbezoo F (2020) Chewing

Efficiency, Global Cognitive

Functioning, and Dentition: A Cross-sectional Observational Study in Older People With Mild Cognitive Impairment or Mild to

Moderate Dementia.

Front. Aging Neurosci. 12:225. doi: 10.3389/fnagi.2020.00225

\section{Chewing Efficiency, Global Cognitive Functioning, and Dentition: A Cross-sectional Observational Study in Older People With Mild Cognitive Impairment or Mild to Moderate Dementia}

\author{
Suzanne Delwel ${ }^{1,2 *}$, Andrea B. Maier ${ }^{3,4}$, Donya Parvaneh ${ }^{2}$, Jesse Meijers ${ }^{5}$, \\ Erik J. A. Scherder ${ }^{1}$ and Frank Lobbezoo ${ }^{2}$
}

${ }^{1}$ Department of Clinical Neuropsychology, Faculty of Behavioral and Movement Sciences, Vrije Universiteit Amsterdam, Amsterdam, Netherlands, ${ }^{2}$ Department of Orofacial Pain and Dysfunction, Academic Centre for Dentistry Amsterdam (ACTA), University of Amsterdam and Vrije Universiteit Amsterdam, Amsterdam, Netherlands, ${ }^{3}$ Department of Medicine and Aged Care, The Royal Melbourne Hospital, University of Melbourne, Melbourne, VIC, Australia, ${ }^{4}$ Department of Human Movement Sciences, Faculty of Behavioural and Movement Sciences, Amsterdam Movement Sciences, Vrije Universiteit Amsterdam, Amsterdam, Netherlands, ${ }^{5}$ Independent Researcher, Amsterdam, Netherlands

Introduction: Previous studies suggest an association between poor mastication and cognitive impairment. The role of chewing efficiency and dentition in this relation is unclear. The aim was to examine global cognitive functioning and dentition as predictors for chewing efficiency, in older people with mild cognitive impairment $(\mathrm{MCl})$ or dementia.

Methods: In this observational cross-sectional study, 136 people with $\mathrm{MCl}$ or dementia were included. The chewing efficiency was assessed with a two-colored chewing gum and analyzed with the Chewing Efficiency Analysis software. The level of global cognitive functioning was measured with the Mini Mental State Examination (MMSE) by trained clinical staff. An oral examination was performed by a dentist and included the number of present teeth, the number of occluding pairs, and the presence of prostheses. Age, gender, and educational years were derived from the medical records. Univariate and multivariate backward stepwise linear regression analyses were used to evaluate global cognitive functioning and dentition as predictors for chewing efficiency.

Results: The mean age of the participants was 82.1 (SD 5.8) years, and 74 (54.4\%) were female. The participants had a median MMSE score of 22.4 (IQR 18.0-26.0) and a median Chewing Efficiency Analysis score of 0.46 (IQR 0.14-0.59). The median number of teeth was 13.0 (IQR 0.0-23.0), and the median number of occluding pairs was 0.0 (IQR 0.0-7.0). Sixty-four (47.4\%) of the participants wore full prosthesis in the upper jaw. In univariate linear regression analyses, predictive factors for the Chewing Efficiency Analysis score were age, MMSE score, full prosthesis in the 
upper jaw, number of present teeth, and number of occluding pairs. In the multivariate model, full prosthesis in the upper jaw and number of occluding pairs were significant predictors for the Chewing Efficiency Analysis score. Participants with full prosthesis in the upper jaw had a lower Chewing Efficiency Analysis score than participants with natural dentition in the upper jaw.

Conclusion: Better mastication is associated with a higher number of occluding pairs. Full prosthesis in the upper jaw is related to a lower chewing efficiency. Global cognitive functioning is not associated with mastication in older people with $\mathrm{MCl}$ or mild-tomoderate dementia. This might be explained by sufficient capacity for compensation of reduced mastication in this group.

Keywords: mastication, chewing, cognitive impairment, cognitive dysfunction, dementia, aged, geriatric dentistry, gerodontology

\section{INTRODUCTION}

Worldwide, around 48 million people have dementia, and this number is estimated to increase to 1.25 billion by 2050 (Prince et al., 2013). Dementia is a clinical syndrome, characterized by memory loss and impairment in language (aphasia or dysphasia), motor function (apraxia), visual recognition (agnosia), and executive functioning, resulting in difficulties during activities in daily life (Kester and Scheltens, 2009). Mild cognitive impairment (MCI) is characterized by a mild impairment of cognition, more than can be expected from age alone, at which daily functioning is largely unaffected (Petersen et al., 2014). The prevalence of MCI increases with age and varies between $6.7 \%$ in people aged $60-64$ years and $25.2 \%$ for $80-84$ years (Petersen et al., 2018). Older people with MCI are at higher risk for developing dementia, among which Alzheimer's disease (AD; Petersen et al., 2018).

At the same time, currently aging individuals maintain their natural dentition until a higher age as a result of better prevention of oral disease and improved professional dental care (Petersen, 2003). However, throughout an individual's life, teeth are lost, mainly as a result of caries and periodontitis (Tonetti et al., 2017), especially in people with dementia, who show a decrease in oral hygiene self-care and professional dental care utilization (Fereshtehnejad et al., 2017). Interestingly, several studies examined the relation between periodontitis, tooth loss, and cognitive impairment (Wu et al., 2016; Delwel et al., 2017, 2018; Tonsekar et al., 2017). Although some of these studies indicate such a relation, the combined results are inconclusive (Wu et al., 2016; Tonsekar et al., 2017). Most of the studies concerning cognition and mastication used the number of present teeth as a measure for mastication (Tada and Miura, 2017). Only a few studies included an objective assessment of chewing efficiency for mastication, such as a mixing ability test (Kimura et al., 2013; Elsig et al., 2015; Weijenberg et al., 2015).

The aim of the current study was to examine global cognitive functioning and dentition as predictors for chewing efficiency, in older people with MCI or dementia. Dentition was represented by the number of teeth, occluding pairs, and the presence of prosthesis.

\section{MATERIALS AND METHODS}

\section{Study Design, Setting, and Participants}

In this cross-sectional study, the relation between chewing efficiency, global cognitive functioning, and dentition was examined in participants with MCI or dementia. The participants were recruited at the geriatric outpatient clinics of the Amsterdam UMC and the Amstelland Hospital in Amstelveen and the psychogeriatric wards of ten nursing homes in Amsterdam and the surrounding area, as part of the Pain in Dementia Amsterdam, or PainDemiA study. The study protocol was approved by the Medical Ethics Review Committee of the Amsterdam UMC (approval number NL 43861.029.13) and was described elsewhere (van Kooten et al., 2015). The study protocol article describes the inclusion and exclusion criteria, power calculation, and procedure to establish the dementia diagnosis. Participants who met the following criteria included: aged 60 or older; diagnosis of MCI or dementia, i.e., $\mathrm{AD}$, vascular dementia $(\mathrm{VaD})$, frontotemporal dementia (FTD), and dementia with Lewy bodies (DLB); and a signed informed consent by the participant or legal representative. In the outpatient memory clinics at the hospitals, the MCI or dementia diagnosis was established by a multidisciplinary team of medical doctors, nurses, neuropsychologists, and neurologists, based on the National Institute of Neurological and Communicative Disorders and Stroke (NINCDS) and the $\mathrm{AD}$ and Related Disorders Association (ADRDA) criteria for Alzheimer dementia (McKhann et al., 2011), the National Institute of Neurological Disorders and Stroke Association (NINDS) and Association Internationale pour la Recherché et l'Enseignement en Neurosciences (AIREN) criteria for vascular dementia (Román et al., 1993), the revised criteria for FTD (Rascovsky et al., 2011), the revised criteria for DLB (McKeith et al., 2005), and the revised criteria for MCI (Petersen et al., 2014). At the nursing homes, the formal dementia diagnosis in the medical chart was used, which was usually based on the Diagnostic and Statistical Manual of Mental Disorders (DSM-IV) criteria for dementia (American Psychiatric Association, 2000). Participants without a MCI or dementia diagnosis were excluded. The data was collected between April 2014 and December 
2015, in accordance with the STrengthening the Reporting of OBservational Studies in Epidemiology (STROBE) statement (Sanderson et al., 2007). The demographic characteristics, gender, date of birth, and educational status were derived from the medical records of the participants.

\section{Global Cognitive Functioning}

The global cognitive functioning of the participants was measured with the Mini Mental State Examination (MMSE) by trained clinical staff at the outpatient clinics of the hospitals and a neuropsychologist at the nursing homes (Folstein et al., 1975). The MMSE screens different cognitive domains: orientation in time and place (10 points), immediate recall ( 3 points), attention and calculation (5 points), delayed recall (3 points), language (8 points), and visual construction (1 point). The minimum score is 0 , and the maximum total score is 30 . Participants with an MMSE score of lower than 14 points were excluded, because understanding of the instructions could not be assumed (Hadjistavropoulos et al., 2010).

\section{Chewing Efficiency}

The chewing efficiency was tested with a two-colored chewing gum, consisting of blue and pink Bubblicious ${ }^{\circledR}$ bubble gum (Cadbury Nederland B.V., Breda, Netherlands). The participants were instructed to chew on the two-colored chewing gum as normally as possible for $1 \mathrm{~min}$. After $60 \mathrm{~s}$, the dentist asked the participants to return the chewing gum, after which it was placed between two clear cellophane sheets to be flattened between two connected acrylic plates. Thereafter, the flattened chewing gum was photographed in a standard setting with a digital Canon $450 \mathrm{D}^{\circledR}$ camera (Canon Inc., Tokyo, Japan; Weijenberg et al., 2013).

The chewing gum photos were analyzed with the Chewing Efficiency Analysis software, according to the algorithm described in Table 1. The minimum Chewing Efficiency Analysis score was 0.00 , and the maximum possible score was 1.00 . The mixture of the two colors was $\sim 25 \%$ for score $0.25, \sim 50 \%$ for score 0.50 , and $\sim 75 \%$ for score 0.75 .

\section{Dentition}

All oral examinations took place by one dentist, experienced in gerodontology, who was blind to the MMSE score at the moment of the examination. The standardized examination took place at the outpatient clinics and nursing homes, with a mouth mirror and head light (Black Diamond, UT, USA). The oral examination included counting of the number of present teeth and the number of occluding pairs (Käyser, 1990). For the number of occluding pairs, a natural premolar contact between the upper and lower jaw counted as one occluding pair and a full natural molar contact as two occluding pairs, resulting in a minimum of 0 occluding pairs and a maximum of 14 occluding pairs. Furthermore, the presence of prosthesis was recorded. At least three occluding pairs or the presence of replacing prosthesis were considered acceptable for chewing ability (Gerritsen et al., 2013).

\section{Statistical Analysis}

The data were analyzed with IBM Statistics SPSS 26 (SPSS Inc., Chicago, IL, USA). The continuous variables were expressed as means and standard deviations (SD) for parametric data and as medians and interquartile ranges (IQR) for nonparametric data. The categorical variables were presented as numbers and percentages. Normality of distribution was assessed with the Shapiro-Wilk test. The means of two continuous dependent variables of two categorical independent variables were compared with the independent $t$-test for parametric data and the Mann-Whitney $U$ test for nonparametric data. The means of two categorical variables were compared with the Pearson chi-square test.

Univariate and multivariate linear regression analyses were performed to identify predictors for Chewing Efficiency Analysis score. Variables with $p<0.10$ in the univariate regression were included in the multivariate backward stepwise analysis to identify the predictors. $p<0.05$ was considered statistically significant. Multicollinearity was identified with the correlation matrix $(r<0.90)$, variance inflation factor $(>10)$, and tolerance statistics $(<0.10)$.

\section{RESULTS}

\section{Participants}

Of the individuals visiting the hospitals, 264 were approached for participation, 203 signed the informed consent letter, and

TABLE 1 | Algorithm of the chewing efficiency analysis.

(1) Divide the photo into squares of $20 \times 20$ pixels each.

(2) For each square:

(a) For each pixel in the square:

(i) Get the R(ed), G(reen), B(lue) values of the color of the pixel.

(ii) Calculate the 3-dimensional spatial distance of the pixel's color and the reference colors Blue, Magenta, Gray, and White, by adding up the absolute difference between the R, G, and B values of both colors being compared.

(iii) Classify the pixel as Blue, Magenta, Gray, or White based on the shortest spatial distance.

(b) Assign a value to the square, based on the categorized pixels in the square:

(i) None-If $>50 \%$ of pixels is White, the square is not counted

(ii) 0.00 - If $>75 \%$ of pixels is Blue

(iii) 0.00 - If $>75 \%$ of pixels is Magenta

(iv) 0.50 - If $>25 \%$ of pixels is Blue and $>25 \%$ of pixels is Magenta

(v) 0.75 - If $>25 \%$ of pixels is Gray and $>25 \%$ of pixels is Blue

(vi) 0.75 - If $>25 \%$ of pixels is Gray and $>25 \%$ of pixels is Magenta

(vii) 1.00 - If $>50 \%$ of pixels is Gray

(3) Calculate the average of the scored squares as the final Chewing Efficiency Analysis score. The value is between 0.00 and 1.00 . 

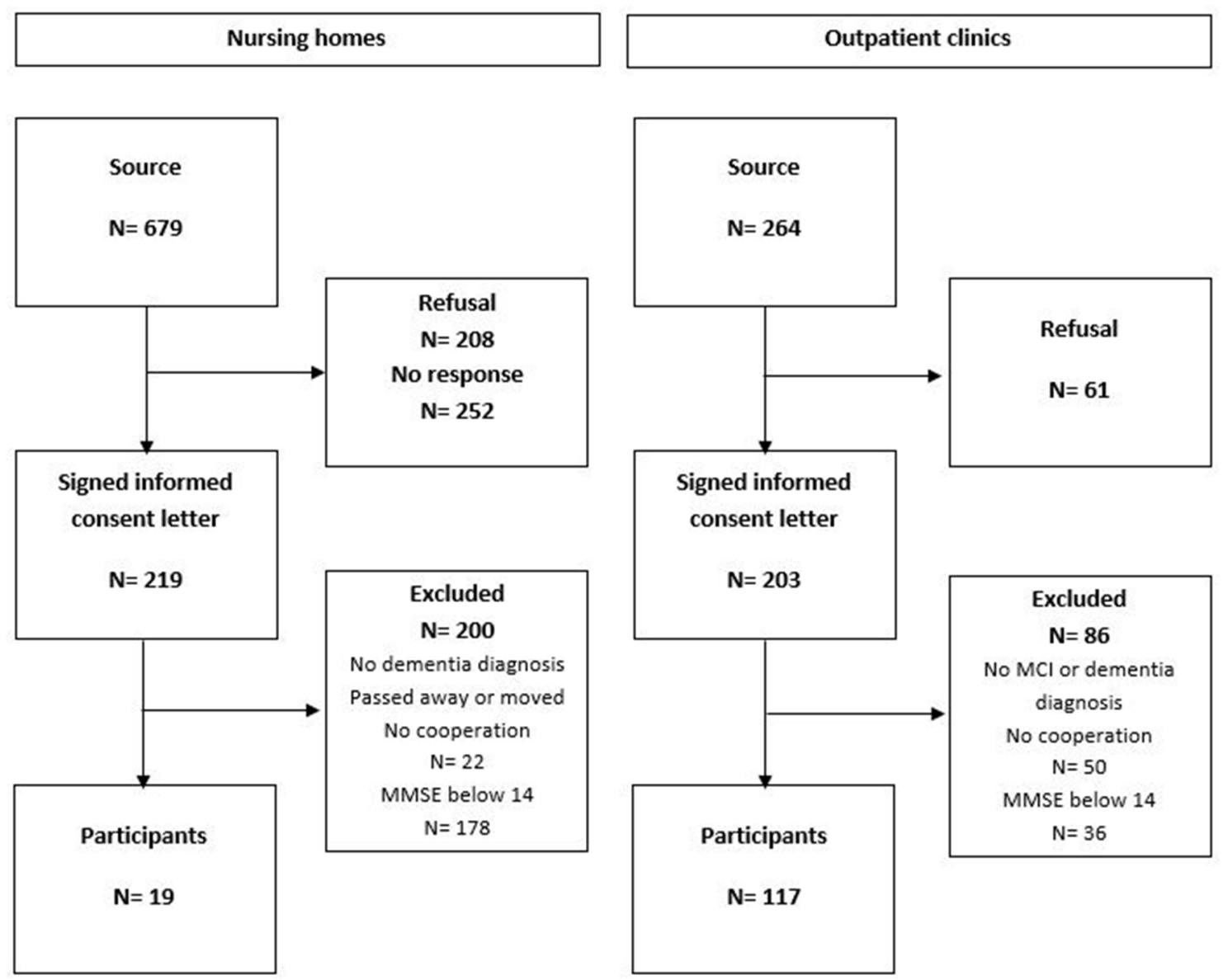

FIGURE 1 | Flow chart of participant inclusion.

117 were included in this study (Figure 1). The main reason for refusal was the expected burden for the participants, and the main reasons for exclusion were the absence of an MCI or dementia diagnosis or an MMSE score lower than 14. For 679 nursing home residents, an informed consent letter was sent to the legal representatives. Following this, 252 did not respond and 208 refused participation. The main reason for refusal was the expected burden for the participants, and the main reason for exclusion was an MMSE score lower than 14. Nineteen nursing home residents remained. In total, 136 persons were included in this study.

\section{Descriptive Data}

Table 2 shows the descriptive data of the 136 participants. The mean age of the participants was 82.1 (SD 5.8) years, and 74 $(=54.4 \%)$ were female. The median number of educational years was 11.0 (IQR 9.0-12.0). The majority of the participants were home-dwelling: 117 (86.0\%).

The participants had a median MMSE score of 23.0 (IQR 18.0-26.0) and a median Chewing Efficiency Analysis score of 0.46 (IQR 0.14-0.59). The median number of teeth was 13.0
(IQR 0.0-23.0), and the median number of occluding pairs was 0.0 (IQR $0.0-7.0$ ). Sixty-four (47.4\%) of the participants wore full prosthesis in the upper jaw. Seventy-one $(52.2 \%)$ of the participants had $0-2$ occluding pairs and wore full or partial prostheses. Thirty-eight (27.9\%) participants had six or more occluding pairs.

On average, the group with full prosthesis in the upper jaw (FPU) was significantly older (mean 84.1, SD 5.6) than the group without FPU, or a dentate upper jaw (mean 80.4, SD 5.5), T-test (df 134) $=-3.93, p=0.000$. The groups were not significantly different concerning gender, $\chi_{(1)}^{2}=2.08, p=0.150$. In addition, the group with FPU included significantly more nursing-home residents than the group without FPU did, $\chi_{(1)}^{2}=9.0$, $p=0.003$.

The group with FPU had no occluding pairs and less present teeth than the group without FPU. The MMSE score was not significantly different for the group with FPU (median 22.0, IQR 18.0-26.0) and the group without FPU (median 23.0, IQR 19.0-27.0). The group with FPU had a significantly lower chewing analysis score (median 0.15, IQR 0.09-0.38) than the group without FPU (median 0.57, IQR 0.46-0.68), $U=532.0$, $p=0.000$. 
TABLE 2 | Descriptive data.

\begin{tabular}{|c|c|c|c|}
\hline Variable & All $(n=135)$ & Full prosthesis upper $(n=64)$ & No full prosthesis (e.g., dentate) upper ( $n=72)$ \\
\hline Age, mean (SD) years & $82.1(5.8)$ & $84.1(5.7)^{* * *}$ & $80.4(5.5)^{* * *}$ \\
\hline Gender, female (\%) & 74 (54.4\%) & 39 (60.9\%) & $35(48.6 \%)$ \\
\hline Education, median (IQR) years & $11.0(9.0-12.0)$ & $9.5(8.0-11.8)^{* * *}$ & $12.0(10.0-14.0)^{* * *}$ \\
\hline Cognition, median (IQR) MMSE score & $23.0(18.0-26.0)$ & $22.0(18.0-26.0)$ & $23.0(19.0-27.0)$ \\
\hline Present teeth, median (IQR) & $13.0(0.0-23.0)$ & $0.0(0.0-6.0)^{* * * *}$ & $22.5(18.3-26.0)^{* * *}$ \\
\hline Occluding pairs, median (IQR) & $0.0(0.0-7.0)$ & $\mathrm{n} / \mathrm{a}$ & $6.0(2.0-9.0)$ \\
\hline \multicolumn{4}{|l|}{ Oral function } \\
\hline 0-2 OP and prosthesis, $N(\%)$ & $71(52.2 \%)$ & $58(90.6 \%)$ & $13(18.1 \%)$ \\
\hline $3-5$ OP, $N(\%)$ & $13(9.6 \%)$ & $\mathrm{n} / \mathrm{a}$ & $13(18.1 \%)$ \\
\hline$\geq 6$ OP, $N(\%)$ & 38 (27.9\%) & $\mathrm{n} / \mathrm{a}$ & 38 (52.8\%) \\
\hline Chewing efficiency, median (IQR) score & $0.46(0.14-0.59)$ & $0.15(0.09-0.38)^{* * *}$ & $0.57(0.46-0.68)^{* * *}$ \\
\hline
\end{tabular}

IQR, interquartile range; MMSE, Mini Mental State Examination; N, number; ${ }^{* *} p<0.01,{ }^{* * *} p<0.001$, OP, occluding pairs; SD, standard deviation.

TABLE 3 | Predictors of the Chewing Efficiency Analysis score in univariate linear regression analysis.

\begin{tabular}{|c|c|c|c|c|c|c|c|}
\hline Variable & $R$ & $R^{2}$ & B & $t$ & $p$ & 95\% Cl Lower & 95\% Cl Upper \\
\hline Age & 0.35 & 0.12 & -0.02 & -4.30 & 0.000 & -0.02 & -0.01 \\
\hline Gender & 0.16 & 0.03 & 0.08 & 1.89 & 0.061 & -0.00 & 0.17 \\
\hline Education & 0.15 & 0.02 & 0.01 & 1.51 & 0.134 & -0.00 & 0.03 \\
\hline Cognition & 0.18 & 0.03 & 0.01 & 2.10 & 0.038 & 0.00 & 0.02 \\
\hline Full prosthesis upper & 0.67 & 0.44 & -0.33 & -10.35 & 0.000 & -0.40 & -0.27 \\
\hline Present teeth & 0.66 & 0.44 & 0.02 & 10.21 & 0.000 & 0.01 & 0.02 \\
\hline Occluding pairs & 0.62 & 0.39 & 0.04 & 9.18 & 0.000 & 0.03 & 0.05 \\
\hline
\end{tabular}

Note: $N=135, B$, unstandardized $B ; C l$, confidence interval; $p$, level of significance; $R$, variance; $t$, test value.

\section{Main Results}

Table 3 shows the predictors of Chewing Efficiency Analysis score in univariate linear regression analysis. The variables age, gender, cognition, full prosthesis upper jaw, number of present teeth, and number of occluding pairs were eligible for the multivariate regression model $(p<0.10)$. The covariate education was excluded $(p=0.134)$.

The correlation matrix (Table 4) indicates a very strong, negative correlation between the number of present teeth and the presence of full prosthesis in the upper jaw $(r=-0.89)$ and a very strong, positive correlation between the number of present teeth and the number of occluding pairs $(r=0.83)$. To avoid multicollinearity, the number of present teeth was excluded from the multivariate regression model.

In multivariate linear backward regression analysis (Table 5), significant predictors for Chewing Efficiency Analysis score were full prosthesis in the upper jaw $(p<0.000)$ and the number of occluding pairs $(p<0.003)$. The final model explained 52\% $\left(R^{2}=0.52\right)$ of the variance in Chewing Efficiency Analysis score, $F_{(3,131)}=47.23, p<0.000$.

\section{DISCUSSION}

The aim of this cross-sectional observational study was to examine global cognitive functioning and dentition as predictors for chewing efficiency in older people with MCI or dementia. One of the main findings was that full prosthesis in the upper jaw and number of occluding pairs were significant predictors for Chewing Efficiency Analysis score. After adjusting for these two predictors and age, the MMSE score was not a significant predictor.

In the current study, a strong, positive correlation was found between the chewing efficiency and the number of teeth present. In a study of Ikebe et al. (2011), a comparable correlation $(r=0.57)$ was found between masticatory performance and the number of residual teeth in a sample of 1,288 communitydwelling, independently living people over the age of 60 years. Furthermore, there was a moderate, negative correlation between age and chewing efficiency in the current study, while there was a weak, negative correlation between age and masticatory performance in the study by Ikebe et al. (2011). In the latter study, gummy jellies were used to measure masticatory performance. Previous research showed a decline in masticatory performance with age, although this decline was not gradual, but stronger in older age (Lin et al., 2017). With aging, the integrity of the white matter of the brain might show a decline, resulting in a lower signal transmission between brain regions (Malykhin et al., 2011). Consequently, neural systems, including the frontal lobe, the striatum, and the cerebellum, involved in mastication among others, may show an age effect (Sesay et al., 2000). Therefore, a reduced masticatory function as part of general aging effect can be expected (Taubert et al., 2020). Additionally, the study by Ikebe et al. (2011) showed that masticatory performance was significantly associated with occlusal bite force and stimulated salivary flow rate. However, the level of global cognitive functioning was not reported.

A study by Kim et al. (2017) involved the level of cognitive impairment, measured with the MMSE of Dementia 
TABLE 4 | Correlation matrix of the Chewing Efficiency Analysis (CEA) score and the predictors.

\begin{tabular}{lcrrrrr}
\hline Correlations & CEA score & Age & Gender & MMSE & FPU & PT \\
\hline CEA score & 1.00 & -0.35 & 0.15 & 0.16 & -0.68 & 0.69 \\
Age & -0.35 & 1.00 & -0.26 & -0.35 & 0.33 & -0.32 \\
Gender & 0.15 & -0.26 & 1.00 & 0.19 & -0.13 & 0.17 \\
Cognition (MMSE) & 0.16 & -0.35 & 0.19 & 1.00 & -0.08 & 0.10 \\
Full prosthesis upper (FPU) & -0.68 & 0.33 & -0.13 & -0.08 & 1.00 & -0.10 \\
Present teeth (PT) & 0.69 & -0.32 & 0.17 & 0.10 & -0.89 & 0.05 \\
Occluding pairs (OP) & 0.62 & -0.30 & 0.12 & 0.05 & -0.71 & 0.71 \\
\hline
\end{tabular}

Note: $N=135$.

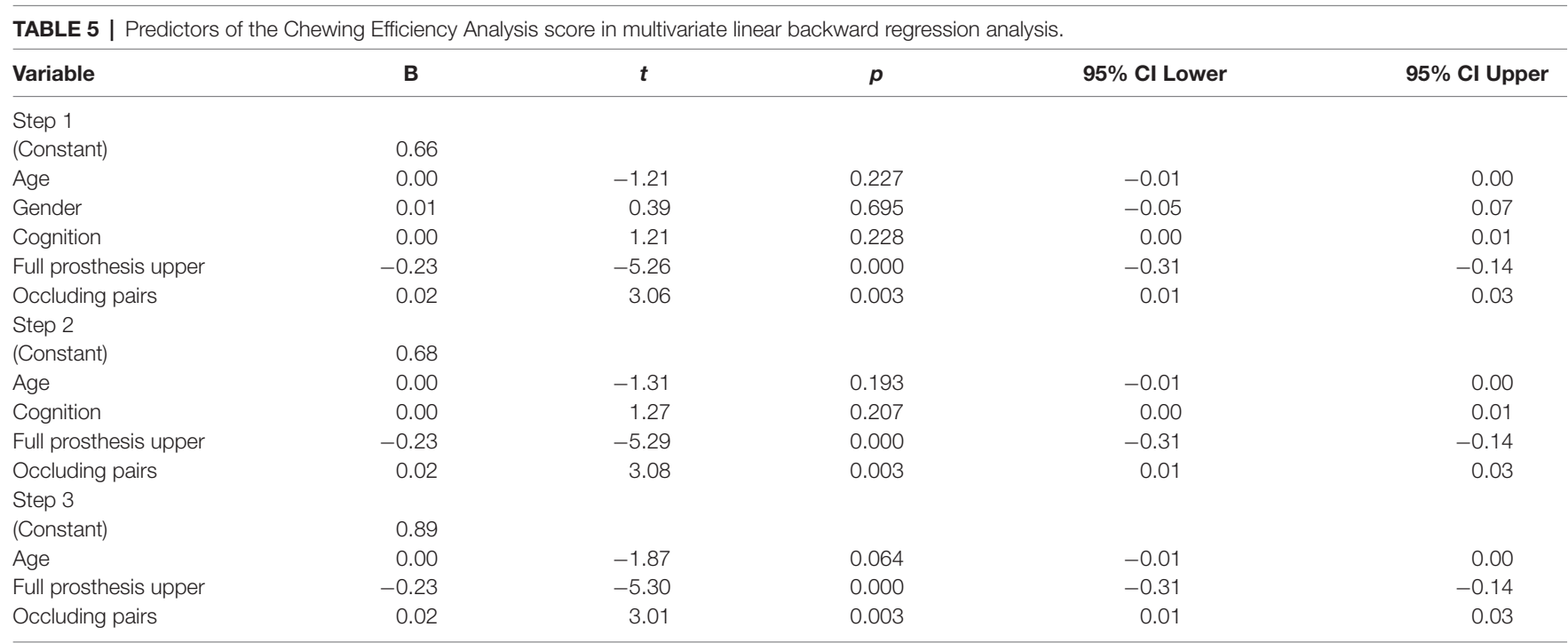

$B$, unstandardized B; Cl, confidence interval; $p$, level of significance; $R$, variance; $t$, test value. $R^{2}=0.53$ and $F=28.64(p<0.000)$ for Step 1. $\Delta R^{2}=0.00$ and $F=35.99(p<0.000)$ for Step 2. $\Delta R^{2}=0.01$ and $F=47.23(p<0.000)$ for Step 3. $N=135$.

Screening (MMSE-DS), and found a significant association with chewing efficiency, measured with a color-changing gum. Furthermore, the study by Kim et al. (2017) reported that participants with a lower chewing efficiency had poorer nutritional status. At the same time, no oral health examination could be done and no correlation could be determined with dentition.

Lexomboon et al. (2012) examined chewing efficiency and tooth loss and the association with cognitive impairment in older people. The study found a significant relation between self-reported chewing efficiency and cognitive function, after adjusting for age, gender, and level of education. The association between tooth loss and cognition was mainly explained by age and education. Both the study by Lexomboon et al. (2012) and the current study found that global cognition had a stronger correlation with age than with the number of teeth present. The difference in chewing efficiency could be explained by the measuring methods of both studies: the study by Lexomboon et al. (2012) used self-reported dental status and chewing difficulty, while the current study included a dental examination by a dentist and a standardized chewing efficiency test. Another explanation might be that people with mild to moderate cognitive impairment still have sufficient capacity for compensation of impairments, such as a reduction in mastication, while this might not be the case in people with severe dementia (Henskens et al., 2018).

People with FPU had a lower chewing efficiency score than people without FPU in the present study, which might be explained by an actual lower chewing efficiency or, alternatively, by the sticking of the chewing gum to the prosthesis. Furthermore, people with prosthesis might also take more time and chewing cycles to achieve the same chewing result (Gonçalves et al., 2014). In addition, people with full prosthesis make smaller vertical and lateral chewing movements than people with natural dentition do (Gonçalves et al., 2014).

Although it is known that age is a risk factor for cognitive decline and tooth loss (Beydoun et al., 2014; Kossioni et al., 2018; Müller et al., 2017), it could also be a risk factor for deterioration in chewing efficiency (Lin et al., 2017; Avivi-Arber and Sessle, 2018).

\section{Strengths and Limitations}

One of the major limitations of this study was that the chewing gum stuck to the prosthesis. Therefore, it was decided to split the data into a group with full prosthesis in the upper jaw and a group without full prosthesis in the upper jaw, or a dentate upper jaw.

Furthermore, the MMSE does not specifically test loss of spatial memory and learning capacity, although these cognitive 
functions might be reduced in relation to reduced masticatory activity (Weijenberg et al., 2011). However, the MMSE tests memory (among other cognitive functions), which is related to the hippocampus as part of a complex memory network. The hippocampus showed degeneration in animal studies after reduced masticatory activity (Yamamoto and Hirayama, 2001; Watanabe et al., 2002; Tsutsui et al., 2007). Another limitation of this study was the MMSE cutoff score of 14. Consequently, people with severe cognitive impairment were excluded, while it could be hypothesized that the chewing efficiency in this group could be affected the most.

At the same time, the MMSE cutoff score of 14 can be seen as a strength, because the participants could be expected to understand the instructions (Hadjistavropoulos et al., 2010). The MMSE is a widely used instrument to screen global cognitive functioning, which makes comparison with other studies and interpretation easier (Folstein et al., 1975). In addition, the non-response rate of the current study was clearly described.

Another strength was that all participants were examined by the same dentist, who had experience in geriatric dentistry and was not informed about the MMSE score of the participants during the dental examination. A structured dental examination took place, instead of using questionnaires to assess the number of teeth present, the number of occluding pairs, and the presence of prostheses. Moreover, the chewing efficiency was measured objectively with a standardized two-colored gum and analyzed with an algorithm programmed specifically for this purpose.

\section{Generalizability}

The current study included a sample of participants with mild to moderate cognitive impairment or mild to moderate dementia, living in the community (86\%) or nursing homes (14\%) in the Netherlands. Following the inclusion criteria of MCI or dementia and the MMSE cutoff score of 14 or higher, it did not include people without cognitive impairment or people with severe cognitive impairment.

\section{Clinical Relevance}

This study showed a strong, positive correlation between the chewing efficiency and the number of teeth present and the number of occluding pairs, indicating that their maintenance is important to maintaining a good chewing efficiency. Tooth loss can lead to chewing difficulties and food deficiencies, affecting general health (Kossioni et al., 2018). The oral healthrelated quality of life (OHRQoL) and chewing efficiency might be restored partially with removable prostheses in people with cognitive impairment or dementia (Campos et al., 2018).

Oral health is important in maintaining food intake, general health, and quality of life (Niesten et al., 2012; Furuta et al., 2013; Peres et al., 2019; van de Rijt et al., 2019). The maintenance of oral health in older people with cognitive impairment requires specialized care (Janssens et al., 2018b; Marchini et al., 2019), including oral health-care assistance by formal and informal caregivers, knowledge about oral health, general health, and cognitive impairment, as well as a multidisciplinary collaboration (Delwel et al., 2018; Jablonski et al., 2018; Janssens et al., 2018a).

\section{Future Research}

For future studies, it is recommended to use an objective measurement for the assessment of chewing efficiency (Weijenberg et al., 2011). For this purpose, a two-colored chewing gum could be used, which is a validated method to evaluate chewing efficiency (Weijenberg et al., 2013). An advantage of the chewing gum is the sweet taste, which could encourage cooperation of study participants. Our clinical observation was that the chewing gum could stick to full prosthesis in the upper jaw. At the same time, Silva et al. specifically studied the reliability of chewing gum in participants with full prosthesis in the upper and lower jaw and concluded that it can be used reliably to assess mastication in this group (Silva et al., 2018). An alternative method to evaluate chewing efficiency in participants with prosthesis is the use of red and blue wax (Speksnijder et al., 2009) or gummy jellies (Ikebe et al., 2011). The Chewing Efficiency Analysis software that was used in the current study is also suitable for the analysis of other materials with contrasting colors (see algorithm in Table 1). In addition to a mixing ability test, the evaluation of maximum voluntary bite force is important to assess the level of functioning of the masticatory system (Speksnijder et al., 2009; Ikebe et al., 2011; Weijenberg et al., 2011).

For the screening of global cognitive functioning, the MMSE is suitable and widely used (Nilsson et al., 2014). In order to study the relation between chewing and cognitive functioning, more specific cognitive tests seem interesting, such as tests for spatial memory and learning capacity (Teixeira et al., 2014; Weijenberg et al., 2018). Moreover, a multifactorial approach is needed, including age, socioeconomic status, cognition, dentition, general health, nutrition, chewing efficiency, inflammatory factors, and stress levels (Azuma et al., 2017; Weijenberg et al., 2018).

\section{CONCLUSION}

Better mastication is associated with a higher number of occluding pairs. Moreover, full prosthesis in the upper jaw is related to a lower chewing efficiency, compared to natural dentition in the upper jaw. Furthermore, global cognitive functioning is not associated with mastication in older people with MCI or mild to moderate dementia, after adjusting for age and dentition. This might be explained by sufficient capacity for compensation of reduced mastication in this group.

\section{DATA AVAILABILITY STATEMENT}

The datasets generated for this study are available on request to the corresponding author.

\section{ETHICS STATEMENT}

The study protocol was reviewed and approved by the Medical Ethics Review Committee of the Amsterdam UMC 
(approval number NL 43861.029.13). The participants or their legal representatives provided written informed consent for participation in this study.

\section{AUTHOR CONTRIBUTIONS}

ES, FL, and SD designed the study. JM developed the Chewing Efficiency Analysis software. SD collected and analyzed the data. SD and DP drafted the manuscript. All authors contributed to the article and approved the submitted version.

\section{FUNDING}

This study was supported by grants from Alzheimer Nederland (WE.09-2012-02), Amstelring (RVB U-9107-2013/HM/wb), Arnold Oosterbaan Hersenstichting, Fonds NutsOhra (1130046), Roomsch Catholijk Oude Armen Kantoor (U-9128$2012 \mathrm{HM} / \mathrm{lw}$ ), Stichting Beroepsopleiding Huisartsen (SBOH), and Stichting Henriëtte Hofje. FL reports grants from Sunstar Suisse, SomnoMed, Goedegebuure, and Airway Management, outside the submitted work.

\section{REFERENCES}

American Psychiatric Association. (2000). Diagnostic and Statistical Manual of Mental Disorders, Fourth Edition, Text Revision (DSM-IV-TR). 3rd Edn. Arlington, VA: American Psychiatric Association.

Avivi-Arber, L., and Sessle, B. J. (2018). Jaw sensorimotor control in healthy adults and effects of ageing. J. Oral Rehabil. 45, 50-80. doi: 10.1111/joor. 12554

Azuma, K., Zhou, Q., Niwa, M., and ya Kubo, K. (2017). Association between mastication, the hippocampus and the HPA axis: a comprehensive review. Int. J. Mol. Sci. 18:1687. doi: 10.3390/ijms18081687

Beydoun, M. A., Beydoun, H. A., Gamaldo, A. A., Teel, A., Zonderman, A. B., and Wang, Y. (2014). Epidemiologic studies of modifiable factors associated with cognition and dementia: systematic review and meta-analysis. BMC Public Health 14:643. doi: 10.1186/1471-2458-14-643

Campos, C. H., Ribeiro, G. R., and Rodrigues Garcia, R. C. M. M. (2018). Mastication and oral health-related quality of life in removable denture wearers with Alzheimer disease. J. Prosthet. Dent. 119, 764-768. doi: 10.1016/j.prosdent. 2017.07.010

Delwel, S., Binnekade, T. T., Perez, R. S. G. M., Hertogh, C. M. P. M., Scherder, E. J. A., and Lobbezoo, F. (2017). Oral health and orofacial pain in older people with dementia: a systematic review with focus on dental hard tissues. Clin. Oral Investig. 21, 17-32. doi: 10.1007/s00784-016-1934-9

Delwel, S., Binnekade, T. T., Perez, R. S. G. M., Hertogh, C. M. P. M., Scherder, E. J. A., and Lobbezoo, F. (2018). Oral hygiene and oral health in older people with dementia: a comprehensive review with focus on oral soft tissues. Clin. Oral Investig. 22, 93-108. doi: 10.1007/s00784-017-2264-2

Elsig, F., Schimmel, M., Duvernay, E., Giannelli, S. V., Graf, C. E., Carlier, S., et al. (2015). Tooth loss, chewing efficiency and cognitive impairment in geriatric patients. Gerodontology 32, 149-56. doi: 10.1111/ger.12079

Fereshtehnejad, S.-M., Garcia-Ptacek, S., Religa, D., Holmer, J., Buhlin, K., Eriksdotter, M., et al. (2017). Dental care utilization in patients with different types of dementia: a longitudinal nationwide study of 58,037 individuals. Alzheimers Dement. 14, 10-19. doi: 10.1016/j.jalz.2017.05.004

Folstein, M. F., Folstein, S. E., and McHugh, P. R. (1975). "Mini-mental state”. A practical method for grading the cognitive state of patients for the clinician. J. Psychiatr. Res. 12, 189-198. doi: 10.1016/0022-3956(75)90026-6

Furuta, M., Komiya-Nonaka, M., Akifusa, S., Shimazaki, Y., Adachi, M., Kinoshita, T., et al. (2013). Interrelationship of oral health status, swallowing

\section{ACKNOWLEDGMENTS}

We thank the participants and their care providers for their cooperation with the study. Furthermore, we thank the staff of the outpatient clinics at the VU Medical Center and the Amstelland Hospital, the staff at the 10 participating nursing homes of Amstelring, Cordaan, and Zonnehuisgroep Amstelland for their cooperation. Moreover, we thank Tarik Binnekade of the Department of Clinical Neuropsychology, Vrije Universiteit Amsterdam, and Janine van Kooten of the Department of General Practice and Elderly Care Medicine, VU University Medical Center, for their help with the acquisition of the participants and the demographic and neuropsychological data collection. Furthermore, we thank the students of the Department of Clinical Neuropsychology, Vrije Universiteit Amsterdam, and the Department of Orofacial Pain and Dysfunction, Academic Centre for Dentistry Amsterdam (ACTA), for their assistance. In addition, we thank Irene Aartman of the Department of Social Dentistry and Maurits van Selms of the Department for Orofacial Pain and Dysfunction, Academic Centre for Dentistry Amsterdam (ACTA), for their statistical support.

function, nutritional status and cognitive ability with activities of daily living in Japanese elderly people receiving home care services due to physical disabilities. Community Dent. Oral Epidemiol. 41, 173-181. doi: 10.1111/cdoe. 12000

Gerritsen, A. E., Witter, D. J., Bronkhorst, E. M., and Creugers, N. H. J. (2013). An observational cohort study on shortened dental arches-clinical course during a period of 27-35 years. Clin. Oral Investig. 17, 859-866. doi: 10.1007/s00784012-0765-6

Gonçalves, T. M. S. V., Vilanova, L. S. R., Gonçalves, L. M., and Rodrigues Garcia, R. C. M. (2014). Effect of complete and partial removable dentures on chewing movements. J. Oral Rehabil. 41, 177-183. doi: 10.1111/joor. 12125

Hadjistavropoulos, T., Fitzgerald, T. D., and Marchildon, G. P. (2010). Practice guidelines for assessing pain in older persons with dementia residing in long-term care facilities. Physiother. Can. 62, 104-113. doi: 10.3138/physio.62. 2.104

Henskens, M., Nauta, I. M., Drost, K. T., and Scherder, E. J. A. (2018). The effects of movement stimulation on activities of daily living performance and quality of life in nursing home residents with dementia: a randomized controlled trial. Clin. Interv. Aging 13, 805-817. doi: 10.2147/cia.s160031

Ikebe, K., Matsuda, K., Kagawa, R., Enoki, K., Yoshida, M., Maeda, Y., et al. (2011). Association of masticatory performance with age, gender, number of teeth, occlusal force and salivary flow in Japanese older adults: is ageing a risk factor for masticatory dysfunction? Arch. Oral Biol. 56, 991-996. doi: 10.1016/j. archoralbio.2011.03.019

Jablonski, R. A., Kolanowski, A. M., Azuero, A., Winstead, V., JonesTownsend, C., and Geisinger, M. L. (2018). Randomised clinical trial: efficacy of strategies to provide oral hygiene activities to nursing home residents with dementia who resist mouth care. Gerodontology 35, 365-375. doi: 10.1111/ger. 12357

Janssens, B., Vanobbergen, J., Lambert, M., Schols, J. M. G. A., and De Visschere, L. (2018a). Effect of an oral healthcare programme on care staff knowledge and attitude regarding oral health: a non-randomised intervention trial. Clin. Oral Investig. 22, 281-292. doi: 10.1007/s00784-017-2110-6

Janssens, B., Vanobbergen, J., Petrovic, M., Jacquet, W., Schols, J. M., and De Visschere, L. (2018b). The impact of a preventive and curative oral healthcare program on the prevalence and incidence of oral health problems in nursing home residents. PLoS One 13:e0198910. doi: 10.1371/journal.pone. 0198910 
Käyser, A. F. (1990). How much reduction of the dental arch is functionally acceptable for the ageing patient? Int. Dent. J. 40, 183-8.

Kester, M. I., and Scheltens, P. (2009). Dementia: the bare essentials. Pract. Neurol. 9, 241-251. doi: 10.1136/jnnp.2009.182477

Kim, E.-K., Lee, S. K., Choi, Y.-H., Tanaka, M., Hirotsu, K., Kim, H. C., et al. (2017). Relationship between chewing ability and cognitive impairment in the rural elderly. Arch. Gerontol. Geriatr. 70, 209-213. doi: 10.1016/j.archger.2017. 02.006

Kimura, Y., Ogawa, H., Yoshihara, A., Yamaga, T., Takiguchi, T., Wada, T., et al. (2013). Evaluation of chewing ability and its relationship with activities of daily living, depression, cognitive status and food intake in the communitydwelling elderly. Geriatr. Gerontol. Int. 13, 718-725. doi: 10.1111/ggi. 12006

Kossioni, A. E., Hajto-Bryk, J., Janssens, B., Maggi, S., Marchini, L., McKenna, G., et al. (2018). Practical guidelines for physicians in promoting oral health in frail older adults. J. Am. Med. Dir. Assoc. 19, 1039-1046. doi: 10.1016/j.jamda.2018. 10.007

Kossioni, A. E., Hajto-Bryk, J., Maggi, S., McKenna, G., Petrovic, M., RollerWirnsberger, R. E., et al. (2018). An expert opinion from the european college of gerodontology and the european geriatric medicine society: european policy recommendations on oral health in older adults. J. Am. Geriatr. Soc. 66, 609-613. doi: 10.1111/jgs.15191

Lexomboon, D., Trulsson, M., Wãrdh, I., and Parker, M. G. (2012). Chewing ability and tooth loss: Association with cognitive impairment in an elderly population study. J. Am. Geriatr. Soc. 60, 1951-1956. doi: 10.1111/j.15325415.2012.04154.x

Lin, C., Wu, C., Wu, S., Lin, H.-H., Cheng, D., and Lo, W. (2017). Agerelated difference in functional brain connectivity of mastication. Front. Aging Neurosci. 9:82. doi: 10.3389/fnagi.2017.00082

Malykhin, N., Vahidy, S., Michielse, S., Coupland, N., Camicioli, R., Seres, P., et al. (2011). Structural organization of the prefrontal white matter pathways in the adult and aging brain measured by diffusion tensor imaging. Brain Struct. Funct. 216, 417-431. doi: 10.1007/s00429-011-0321-1

Marchini, L., Ettinger, R., Caprio, T., and Jucan, A. (2019). Oral health care for patients with Alzheimer's disease: an update. Spec. Care Dent. 39, 262-273. doi: $10.1111 /$ scd.12375

McKeith, I. G., Dickson, D. W., Lowe, J., Emre, M., O’Brien, J. T., Feldman, H., et al. (2005). Diagnosis and management of dementia with lewy bodies: third report of the DLB consortium. Neurology 65, 1863-1872. doi: 10.1212/wnl.65. 12.1992-a

McKhann, G. M., Knopman, D. S., Chertkow, H., Hyman, B. T., Jack, C. R., Kawas, C. H., et al. (2011). The diagnosis of dementia due to Alzheimer's disease: recommendations from the National Institute on Aging-Alzheimer's Association workgroups on diagnostic guidelines for Alzheimer's disease. Alzheimers Dement. 7, 263-269. doi: 10.1016/j.jalz.2011.03.005

Müller, F., Shimazaki, Y., Kahabuka, F., and Schimmel, M. (2017). Oral health for an ageing population: the importance of a natural dentition in older adults. Int. Dent. J. 67, 7-13. doi: 10.1111/idj.12329

Niesten, D., Van Mourik, K., and Van Der Sanden, W. (2012). The impact of having natural teeth on the QoL of frail dentulous older people. A qualitative study. BMC Public Health 12:1. doi: 10.1186/1471-2458-12-839

Nilsson, H., Berglund, J., and Renvert, S. (2014). Tooth loss and cognitive functions among older adults. Acta Odontol. Scand. 72, 639-44. doi: 10.3109/00016357. 2014.882983

Peres, M. A., Macpherson, L. M. D., Weyant, R. J., Daly, B., Venturelli, R., Mathur, M. R., et al. (2019). Oral diseases: a global public health challenge. Lancet 394, 249-260. doi: 10.1016/S0140-6736(19)31146-8

Petersen, P. E. (2003). The World Oral Health Report 2003: continuous improvement of oral health in the 21st century--the approach of the WHO global oral health programme. Community Dent. Oral Epidemiol. 31, 3-23. doi: 10.1046/j.2003.com122.x

Petersen, R. C., Caracciolo, B., Brayne, C., Gauthier, S., Jelic, V., and Fratiglioni, L. (2014). Mild cognitive impairment: a concept in evolution. J. Intern. Med. 275, 214-228. doi: 10.1111/joim.12190

Petersen, R. C., Lopez, O., Armstrong, M. J., Getchius, T. S. D., Ganguli, M., Gloss, D., et al. (2018). Practice guideline update summary: mild cognitive impairment. Neurology 90, 126-135. doi: 10.1212/WNL.0000000000 006038
Prince, M., Bryce, R., Albanese, E., Wimo, A., Ribeiro, W., and Ferri, C. P. (2013). The global prevalence of dementia: a systematic review and metaanalysis. Alzheimers Dement. 9, 63-75.e2. doi: 10.1016/j.jalz.2012. 11.007

Rascovsky, K., Hodges, J. R., Knopman, D., Mendez, M. F., Kramer, J. H., Neuhaus, J., et al. (2011). Sensitivity of revised diagnostic criteria for the behavioural variant of frontotemporal dementia. Brain 134, 2456-77. doi: 10.1093/brain/awr179

Román, G. C., Tatemichi, T. K., Erkinjuntti, T., Cummings, J. L., Masdeu, J. C., Garcia, J. H., et al. (1993). Vascular dementia: diagnostic criteria for research studies. Report of the NINDS-AIREN International Workshop. Neurology 43, 250-60. doi: 10.1212/wnl.43.2.250

Sanderson, S., Tatt, I. D., and Higgins, J. P. T. (2007). Tools for assessing quality and susceptibility to bias in observational studies in epidemiology: a systematic review and annotated bibliography. Int. J. Epidemiol. 36, 666-676. doi: $10.1093 / \mathrm{ije} / \mathrm{dym} 018$

Sesay, M., Tanaka, A., Ueno, Y., Lecaroz, P., and De Beaufort, D. G. (2000). Assessment of regional cerebral blood flow by xenon-enhanced computed tomography during mastication in humans. Keio J. Med. 49, A125-A128.

Silva, L. C., Nogueira, T. E., Rios, L. F., Schimmel, M., and Leles, C. R. (2018). Reliability of a two-colour chewing gum test to assess masticatory performance in complete denture wearers. J. Oral Rehabil. 45, 301-307. doi: 10.1111/joor. 12609

Speksnijder, C. M., Abbink, J. H., Van Der Glas, H. W., Janssen, N. G., and Van Der Bilt, A. (2009). Mixing ability test compared with a comminution test in persons with normal and compromised masticatory performance. Eur. J. Oral Sci. 117, 580-586. doi: 10.1111/j.1600-0722.2009.00675.x

Tada, A., and Miura, H. (2017). Association between mastication and cognitive status: a systematic review. Arch. Gerontol. Geriatr. 70, 44-53. doi: 10.1016/j. archger.2016.12.006

Taubert, M., Roggenhofer, E., Melie-Garcia, L., Muller, S., Lehmann, N., Preisig, M., et al. (2020). Converging patterns of aging-associated brain volume loss and tissue microstructure differences. Neurobiol. Aging 88, 108-118. doi: 10.1016/j.neurobiolaging.2020.01.006

Teixeira, F. B., Pereira Fernandes, L. M., Noronha, P. A. T., dos Santos, M. A. R., Gomes-Leal, W., Ferraz Maia, C. S., et al. (2014). Masticatory deficiency as a risk factor for cognitive dysfunction. Int. J. Med. Sci. 11, 209-14. doi: 10.7150/ijms.6801

Tonetti, M. S., Bottenberg, P., Conrads, G., Eickholz, P., Heasman, P., Huysmans, M.-C., et al. (2017). Dental caries and periodontal diseases in the ageing population: call to action to protect and enhance oral health and well-being as an essential component of healthy ageing - Consensus report of group 4 of the joint EFP/ORCA workshop on the boundaries be. J. Clin. Periodontol. 44, S135-S144. doi: 10.1111/jcpe.12681

Tonsekar, P. P., Jiang, S. S., and Yue, G. (2017). Periodontal disease, tooth loss and dementia: is there a link? A systematic review. Gerodontology 34, 151-163. doi: $10.1111 /$ ger.12261

Tsutsui, K., Kaku, M., Motokawa, M., Tohma, Y., Kawata, T., Fujita, T., et al. (2007). Influences of reduced masticatory sensory input from soft-diet feeding upon spatial memory/learning ability in mice. Biomed. Res. 28, 1-7. doi: 10.2220/biomedres.28.1

van de Rijt, L. J. M., Stoop, C. C., Weijenberg, R. A. F., de Vries, R., Feast, A. R., Sampson, E. L., et al. (2019). The influence of oral health factors on the quality of life in older people: a systematic review. Gerontologist XX, 1-17. doi: 10.1093/geront/gnz105

van Kooten, J., Delwel, S., Binnekade, T. T., Smalbrugge, M., Van Der Wouden, J. C., Perez, R. S. G. M., et al. (2015). Pain in dementia: prevalence and associated factors: protocol of a multidisciplinary study. BMC Geriatr. 15:29. doi: 10.1186/s12877-015-0025-0

Watanabe, K., Ozono, S., Nishiyama, K., Saito, S., Tonosaki, K., Fujita, M., et al. (2002). The molarless condition in aged SAMP8 mice attenuates hippocampal Fos induction linked to water maze performance. Behav. Brain Res. 128, 19-25. doi: 10.1016/s0166-4328(01)00268-6

Weijenberg, R. A. F., Delwel, S., Ho, B., Van van der Maarel-Wierink, C. D., and Lobbezoo, F. (2018). Mind your teeth-The relationship between mastication and cognition. Gerodontology 36, 2-7. doi: 10.1353/book. 49273 
Weijenberg, R. A. F., Lobbezoo, F., Visscher, C. M., and Scherder, E. J. A. (2015). Oral mixing ability and cognition in elderly persons with dementia: a cross-sectional study. J. Oral Rehabil. 42, 481-486. doi: 10.1111/joor. 12283

Weijenberg, R. A. F., Scherder, E. J. A., and Lobbezoo, F. (2011). Mastication for the mind-The relationship between mastication and cognition in ageing and dementia. Neurosci. Biobehav. Rev. 35, 483-497. doi: 10.1016/j.neubiorev.2010. 06.002

Weijenberg, R. A. F., Scherder, E. J. A., Visscher, C. M., Gorissen, T., Yoshida, E., and Lobbezoo, F. (2013). Two-colour chewing gum mixing ability: digitalisation and spatial heterogeneity analysis. J. Oral Rehabil. 40, 737-743. doi: 10.1111/joor.12090

Wu, B., Fillenbaum, G. G., Plassman, B. L., and Guo, L. (2016). Association between oral health and cognitive status: a systematic review. J. Am. Geriatr. Soc. 64, 739-51. doi: 10.1111/jgs. 14572
Yamamoto, T., and Hirayama, A. (2001). Effects of soft-diet feeding on synaptic density in the hippocampus and parietal cortex of senescence-accelerated mice. Brain Res. 902, 255-63. doi: 10.1016/s0006-8993(01)02410-6

Conflict of Interest: The authors declare that the research was conducted in the absence of any commercial or financial relationships that could be construed as a potential conflict of interest.

Copyright (C) 2020 Delwel, Maier, Parvaneh, Meijers, Scherder and Lobbezoo. This is an open-access article distributed under the terms of the Creative Commons Attribution License (CC BY). The use, distribution or reproduction in other forums is permitted, provided the original author(s) and the copyright owner(s) are credited and that the original publication in this journal is cited, in accordance with accepted academic practice. No use, distribution or reproduction is permitted which does not comply with these terms. 